\title{
SENSOR GETARAN DUA DIMENSI (2-D) BERBASIS KOIL DATAR UNTUK MENGUKUR FREKUENSI GETARAN GEMPA DI WILAYAH LOMBOK NUSA TENGGARA BARAT
}

\author{
Islahudin', M. Firman Ramadhan ${ }^{2}$ \\ ${ }^{1,2}$ Dosen Program Studi Pendidikan Fisika FKIP, Universitas Muhammadiyah Mataram \\ Email: islahudin.ntb@gmail.com
}

\begin{abstract}
ABSTRAK
Pada penelitian ini telah dirancang aplikasi koil datar sebagai sensor getaran untuk deteksi dini gempa. Koil datar adalah lilitan kawat yang sangat tipis dan bertindak sebagai induktor. Koil datar ini bersama dengan kapasitor membangun sebuah osilator yang menghasilkan frekuensi bergantung pada nilai induktansi dan kapasitansi. Osilator ini dinamakan osilator LC. Induktansi koil datar bergantung pada jarak benda logam di depan koil datar. Jika induktansi berubah, frekuensi akan berubah juga. Frekuensi dapat dirubah ke dalam bentuk tegangan untuk merepresentasikan jarak. Efek ini kemudian diterapkan pada frekuensi rendah menggunakan bandul pada rumahan sensor. Berdasarkan penelitian, sensor getaran untuk mendeteksi gempa bumi sudah dirancang serta masih dalam proses pengujian dan kalibrasi. Sensor getaran yang sudah dibuat adalah sensor koil datar arah $\mathrm{x}$ da arah $\mathrm{y}$. Frekuensi getaran yang sudah bisa diukur dalam arah $\mathrm{x}$ adalah 0,468 $\mathrm{Hz}$. Nilai ini hampir sama dengan frekuensi sumber getaran sebesar $0,46 \mathrm{~Hz}$. Adapun frekuensi yang getaran yang sudah bisa diukur dalam arah y adalah $0,55 \mathrm{~Hz}$ dan nilai ini hampir sama dengan frekuensi sumber getaran sebesar $0,5 \mathrm{~Hz}$.
\end{abstract}

Kata kunci: koil datar, sensor getaran, dua dimensi (2-D), gempa

\section{PENDAHULUAN}

Indonesia merupakan negara yang memiliki sumber gempa yang cukup banyak. Salah satu wilayah yang berada pada jalur gempa adalah pulau lombok, Provinsi Nusa Tenggara Barat. Pulau lombok merupakan wilayah kecil yang berada pada perbatasan antara lempeng besar asia dengan lempeng australia. Gempa bumi yang pernah terjadi pada wilayah ini cukup meresahkan masyarakat, walaupun skalanya tidak begitu besar seperti yang terjadi pada daerah lain di Indonesia. Gempa bumi yang pernah melanda wilayah ini terakhir terjadi pada awal tahun 2013 silam. Guncangan akibat gempa bumi tersebut dirasakan oleh sebagian besar masyarakat lombok khususnya dan wilayah NTB pada umumnya. Adapun kerusakan yang cukup parah terjadi di wilayah Kabupaten Lombok Utara. Meskipun tidak menimbulkan korban jiwa namun kerugian material akibat bencana alam tersebut ditaksir mencapai ratusan juta rupiah.

Gempa merupakan getaran yang menjalar ke segala arah melalui sebuah material yang mengakibatkan fisik material tersebut menjadi berubah baik dalam skala kecil maupun skala besar. Wilayah yang dilalui gempa biasanya mencakup wilayah yang sangat luas. Oleh karena itu, diperlukan sensor getaran yang dapat mendeteksi getaran dalam arah 2 dimensi (2-D). Dalam penelitian ini, peneliti telah merancang sensor getaran dua dimensi yang dapat mengukur frekuensi gempa dari sisi besar dan arahnya.

Adapun frekuensi getaran gempa yang dirancang pada penelitian ini adalah frekuensi rendah. Untuk aplikasi pada getaran frekuensi rendah ini, pada penelitian sebelumnya (Hibah Penelitian Dosen Pemula Tahun 2013) telah dilakukan penelitian tentang sensor getaran frekuensi rendah berbasis koil datar ${ }^{[1]}$. Pada penelitian ini telah diperoleh hasil pengukuran sensor getaran frekuensi rendah dengan daerah pengukuran mulai dari $0,08 \mathrm{~Hz}$ sampai $1 \mathrm{~Hz}$. Pada penelitian yang telah dilakukan tersebut, getaran yang dideteksi merupakan getaran dalam 1 dimensi saja. Keunggulan dari sensor getaran 2-D (dua dimensi) ini adalah dapat memberikan informasi tentang besar dan arah dari getaran yang sedang terjadi. Hal ini karena pada dasarnya getaran suatu objek menjalar ke segala arah. Selain itu, sensor getaran dua dimensi (2-D) juga menggunakan elemen sensor yang banyak terdapat di pasaran sebagaimana pada penelitian sebelumnya yaitu Penelitian Hibah 
Dosen Pemula Tahun Anggaran 2013 untuk sensor getaran satu dimensi saja.

Kondisi tersebutlah yang membuat peneliti mendesain dan membuat sensor getaran dua dimensi (2-D) frekuensi rendah berbasis koil datar sebagai alat pengindranya. Dengan bantuan perangkat lunak, diperoleh suatu alat ukur getaran frekuensi rendah beserta amplitudonya yang sederhana, mempunyai ketelitian tinggi dan biaya yang murah. Pada penelitian ini disertakan pengukuran jarak dan diukur responnya terhadap tegangan keluaran, selain itu tentunya dilakukan pengukuran getaran untuk frekuensi rendah dalam arah dua dimensi (2-D). Pengukuran jarak dilakukan karena pada hakikatnya bahwa getaran tersebut merupakan jarak yang berubah-ubah yang mempunyai posisi secara periodik. Adapun tujuan dari penelitian ini adalah (1)membuat rangkaian pengolah sinyal keluaran dari sensor getaran dua dimensi (2D). (2)membuat rumahan sensor getaran dua dimensi (2-D) dan (3)membuat perangkat lunak sensor getaran dua dimensi (2-D). Pengembangan selanjutnya dari hasil penelitian tentang sensor getaran ini adalah sensor sensor getaran untuk mengukur frekuensi gempa tiga dimensi (3-D).

\section{METODE PENELITIAN}

A. Desain Kalibrator Frekuensi Rendah Sensor koil datar yang dirancang adalah untuk mendeteksi getaran frekuensi rendah. Karena itu, perlu dibuat rangkaian yang dapat menghasilkan getaran frekuensi rendah khususnya di bawah $1 \mathrm{~Hz}$. Selain frekuensi 1 $\mathrm{Hz}$, dibuat juga kalibrator sampai $10 \mathrm{~Hz}$ dengan cara menambahkan gir konversi pada kalibrator $1 \mathrm{~Hz}$, tujuannya adalah untuk mengetahui frekuensi karaktristik sensor. Gambar sistem tersebut, dapat dilihat pada Gambar 1 di bawah ini.

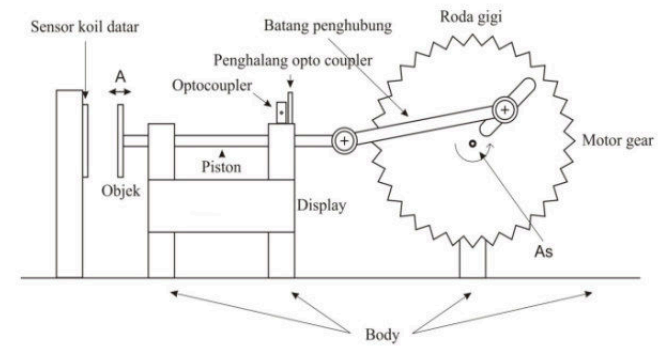

Gambar 1. Sistem mekanik kalibrator frekuensi rendah
Sistem ini terdiri dari motor gear, batang penghubung, sensor optokopler, objek, dan sensor koil datar. Kecepatan putaran motor gear ini dapat diatur dengan potensio yang kemudian diteruskan ke batang penghubung ke objek. Dapat dilihat dari gambar bahwa jika motor berputar maka objek akan bergerak bolak-balik secara horizontal. Pada batang penghubung dipasang barier atau penghalang untuk sensor optokopler sehingga frekuensi pergerakan batang dapat dihitung.

\section{B. Desain Mekanik Sensor Getaran}

Aplikasi akhir dari sensor koil datar adalah untuk mendeteksi getaran frekuensi rendah khususnya untuk mendeteksi adanya gempa bumi dalam arah dua dimensi (2-D). Gempa bumi merupakan getaran yang selain memiliki besar, juga memiliki arah. Adapun mekanik sensor tampak pada Gambar 2 berikut.

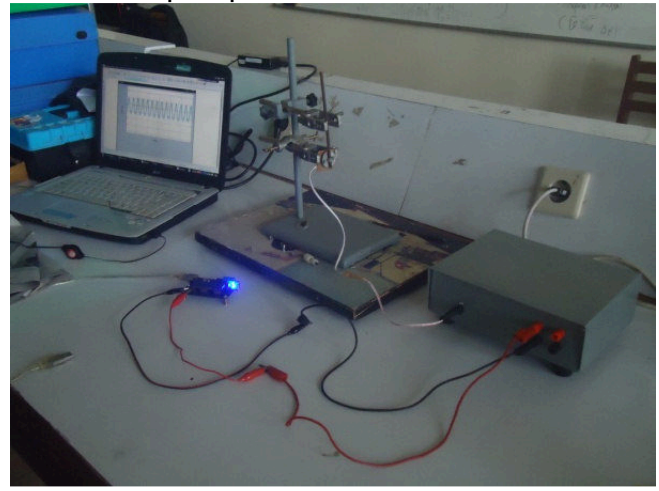

Gambar 2. Mekanik sensor getaran (Sumber: Arsip Hibah PDP 2013)

Adapun bentuk mekanik sensor getaran dua dimensi (2-D) tampak pada Gambar 3 berikut.

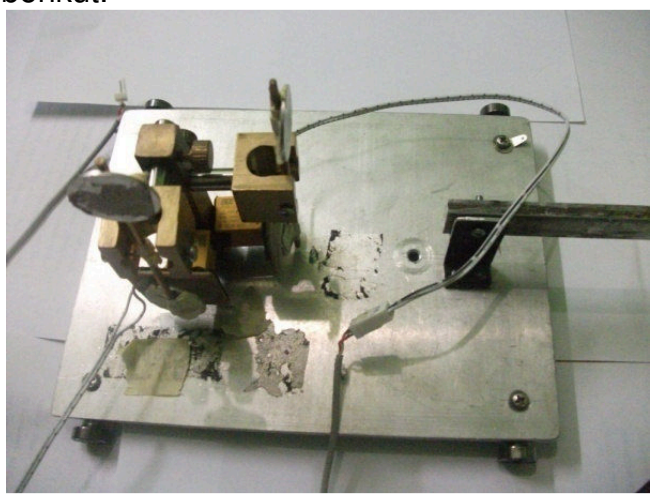

Gambar 3. Mekanik sensor getaran 2-D 
Mekanik sensor ini tersusun dari sensor koil datar dan bandul yang dipasang sedemkian sehingga mampu mendeteksi getaran. Bahan pengganggu pada koil datar dapat menjauh dan mendekati koil datar sesuai dengan gerakan harmonis bandul terhadap titik seimbangnya.

Elemen koil datar yang digunakan terbuat dari PCB yang dibuat jalur-jalur sebanyak 30 lilitan berdiameter $3 \mathrm{~cm}$ dengan nilai masingmasing induktansi sebesar 7,8 $\mu \mathrm{H}$. Gambar di bawah ini adalah salah satu elemen koil datar. Adapun bentuk koil datar tampak pada Gambar 4 berikut.

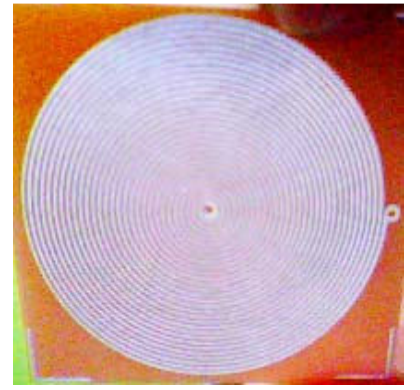

Gambar 4. Elemen koil datar

\section{Rangkaian Pengolah Isyarat Analog}

Rangkaian pengolah isyarat analog terdiri dari pengolah isyarat sensor, filter dan penguat diferensial. Blok diagram dari rangkaian pengolah isyarat analog ini dapat dilihat pada diagram di bawah ini.

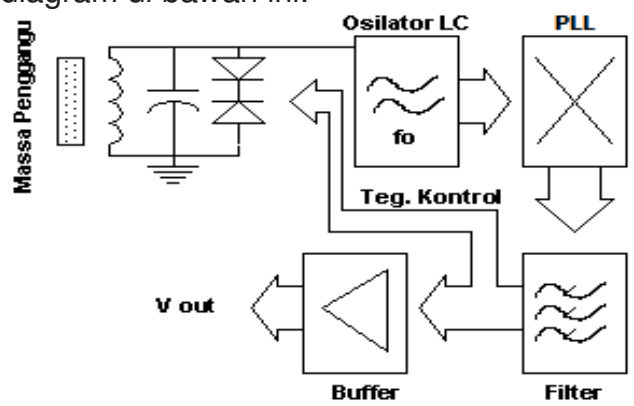

Gambar 5. Blok diagram rangkaian pengolah isyarat analog

\section{Rangkaian Digital dan Pengiriman Data}

Untuk meningkatkan unjuk kerja alat dalam melakukan akuisisi data hasil pengukuran, maka digunakan rangkaian mikrokontroler atmega 16 dan tampilan pada PC. Adapun software yang digunakan untuk menampilkan dan merekam data hasil pengukuran adalah Visual Basic 2008 dan Procesing, dikombinasikan dengan perhitungan Fast Transform Fourier (FFT) serta Microsof Excel. Analisis data hasil penelitian diperoleh menggunakan FFT untuk mengitung frekuensi getaran objek.

\section{HASIL DAN PEMBAHASAN}

A. Hasil Penelitian

Karakteristik Statik Sensor Arah

Sensor koil datar memiliki respon terhadap perubahan jarak dengan terjadinya perubahan tegangan. Adapun hasil pengukuran respon sensor arah $\mathrm{x}$ terhadap jarak tampak pada Gambar 6 berikut.

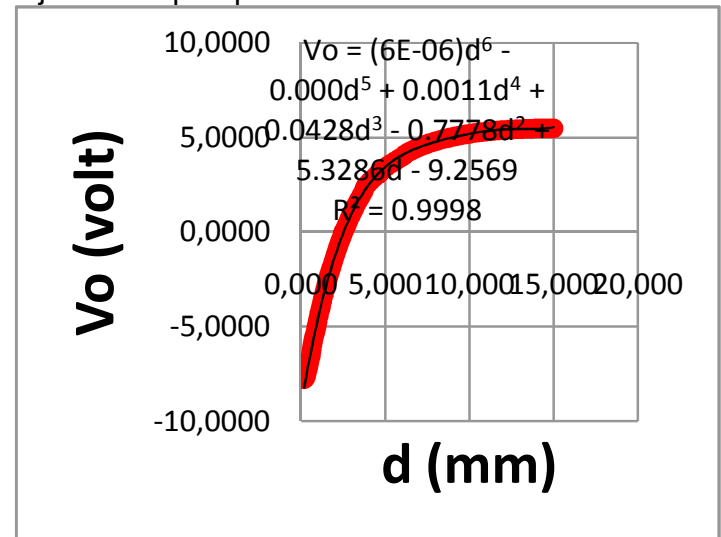

Gambar 6. Respon sensor arah $x$ terhadap perubahan jarak

Adapun hasil pengukuran respon sensor arah y terhadap jarak tampak pada Gambar 7 berikut.

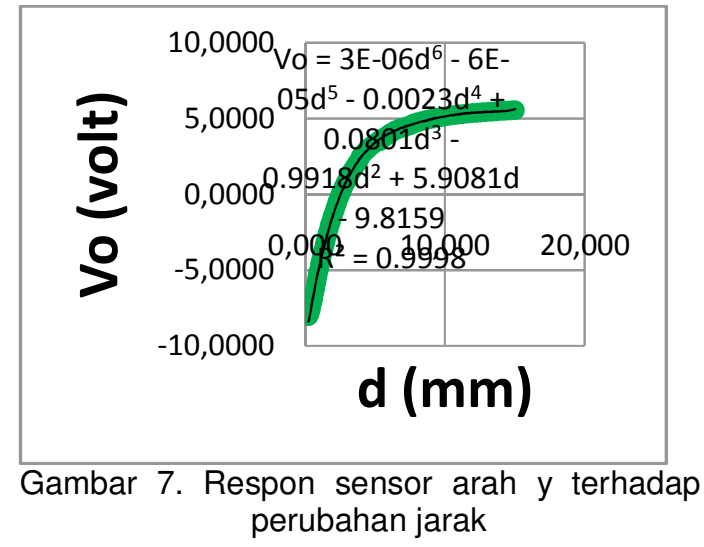

Berdasarkan grafik pada Gambar 7, di atas, maka daerah kerja sensor $x$ dan sensor y yang dapat diambil adalah antara $0.250-4.050$ 
$\mathrm{mm}$. Kurva pada daerah tersebut membentuk hasil yang kontinu sehingga diperkirakan dapat didekati dengan suatu fungsi dengan baik. Daerah kurva yang lebih kecil dari $0.250 \mathrm{~mm}$ terlihat sudah mulai mengalami nilai yang tetap (saturasi) sehingga tidak kontinu dengan data yang lainnya, sehingga hal ini akan sulit untuk didekati dengan suatu fungsi. Oleh karena itu, data pada daerah ini tidak dimasukkan pada daerah kerja dari ketiga sensor.

Adapun grafik daerah kerja sensor arah $\mathrm{x}$ tampak pada Gambar 8 berikut.

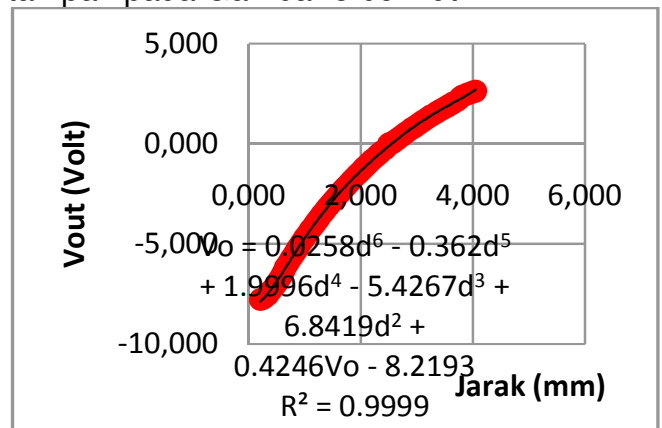

Gambar 8. Daerah Kerja Sensor Arah x

Sedangkan grafik daerah kerja sensor arah y tampak pada Gambar 9 berikut.

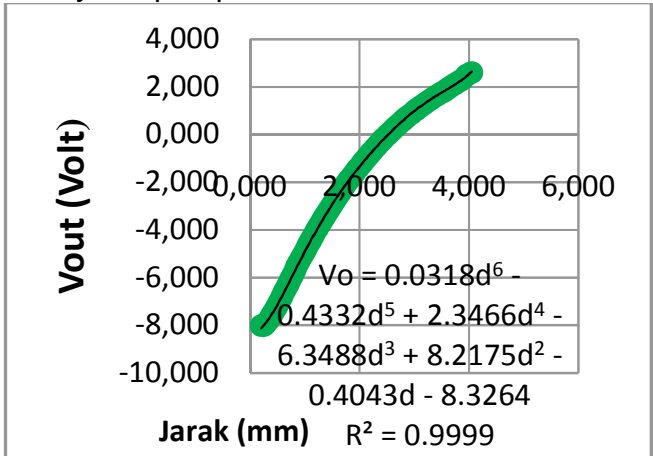

Gambar 9. Daerah Kerja Sensor Arah y

Berdasarkan grafik pada Gambar 8 maupun Gambar 9 diatas, tampak bahwa daerah yang paling sensitif keluaran sensor terletak pada daerah tegangan keluaran yang bernilai negatif atau pada jarak yang dekat, yaitu $0,2 \mathrm{~mm}$ sampai $2 \mathrm{~mm}$. Pada daerah ini terjadi perubahan tegangan keluaran yang besar untuk sedikit perubahan jarak antara koil datar dengan bahan pengganggu. Gambar 10 menunjukkan daerah sensitif maksimum sensor arah $\mathrm{x}$.

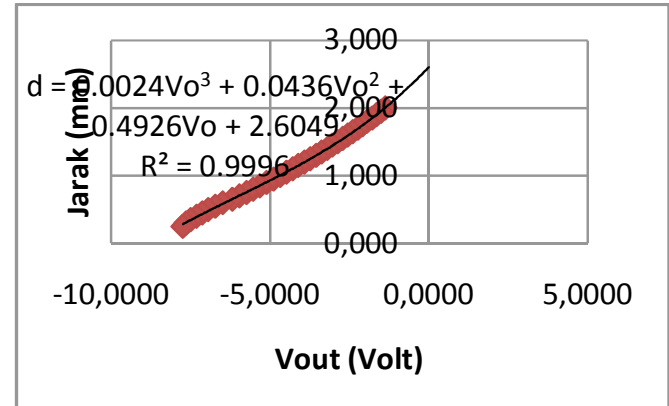

Gambar 10. Daerah sensitif maksimum dari keluaran sensor arah $\mathrm{x}$

Adapun daerah sensitif maksimum dari keluaran sensor arah y tampak pada Gambar 11 berikut.

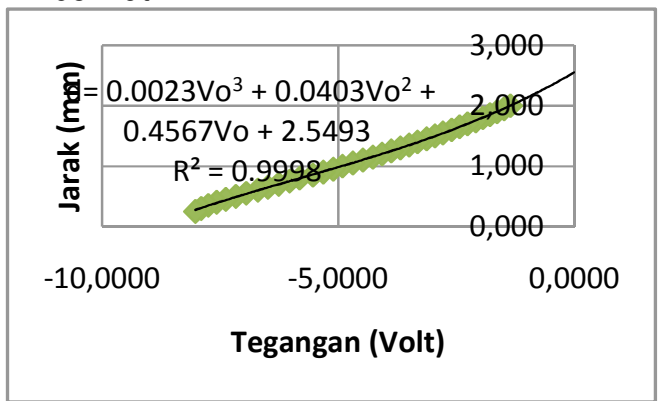

Gambar 11. Daerah sensitif maksimum dari keluaran sensor arah y

Berdasarkan Gambar 11 di atas, kesalahan absolut sensor arah $\mathrm{x}$ pada daerah sensitifitas maksimum tampak pada Gambar 12 berikut.

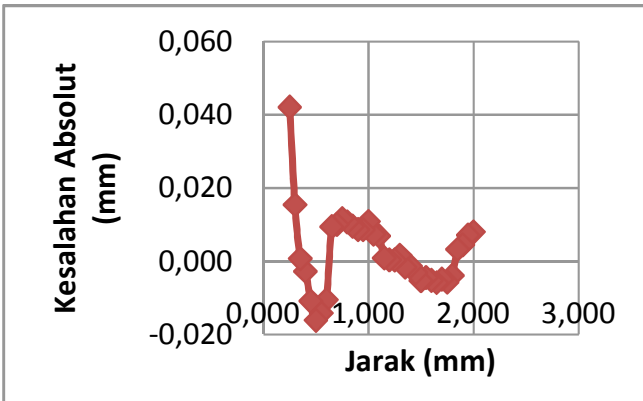

Gambar 12. Kesalahan absolut pada daerah sensitivitas maksimum sensor $\operatorname{arah} \mathrm{x}$.

Adapun kesalahan absolut sensor arah y pada daerah sensitifitas maksimum tampak pada Gambar 13 berikut. 


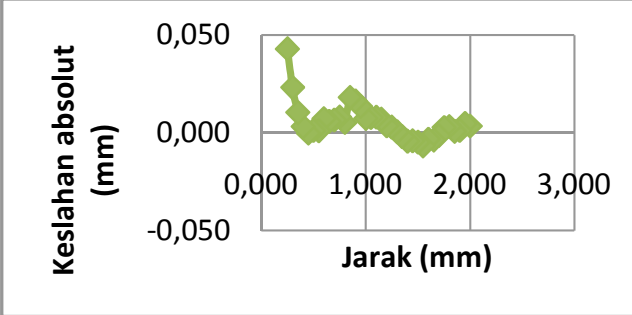

Gambar 13. Kesalahan absolut pada daerah sensitivitas maksimum sensor arah $\mathrm{y}$.

Berdasarkan kurva di atas terlihat bahwa kesalahan absolut maskimum pada sensor arah $\mathrm{x}$ dan $\mathrm{y}$ masing-maing adalah sebesar $0,042 \mathrm{~mm}$ dan 0,043 mm. Dengan demikian ketelitian maksimum sensor koil datar arah $\mathrm{x}$ dan y terhadap jarak adalah sebesar 0,042 $\mathrm{mm}$ dan 0,043 mm. Besarnya nilai penyimpangan maksimum ini diakibatkan karena cepatnya perubahan nilai tegangan sehingga kemungkinan terjadi kesalahan paralaks dalam pembacaan nilai tegangan.

Berdasarkan hasil kesalahan absolut di atas dapat diketahui kesalahan relatif hasil pendekatan persamaan yang digunakan. Penentuan kesalahan relatif melibatkan daerah kerja sensor. Untuk sensor arah $\mathrm{x}$ daerah kerja maksimum yang diambil adalah 2,000 $\mathrm{mm}$ dan daerah kerja minimum adalah $0.250 \mathrm{~mm}$, sehingga kesalahan relatifnya tampak pada gambar berikut.

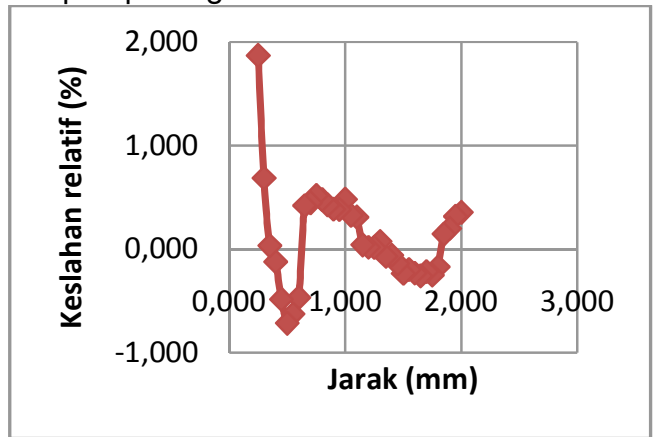

Gambar 14. Kesalahan relatif pada daerah sensitivitas maksimum sensor koil datar $\operatorname{arah} \mathrm{x}$.

Dari grafik di atas, dapat diketahui kesalahan relatif maksimum sensor koil datar adalah $1,87 \%$.

Untuk sensor arah y daerah kerja maksimum yang diambil adalah 2,000 $\mathrm{mm}$ dan daerah kerja minimum adalah $0.250 \mathrm{~mm}$, sehingga kesalahan relatifnya tampak pada gambar berikut.

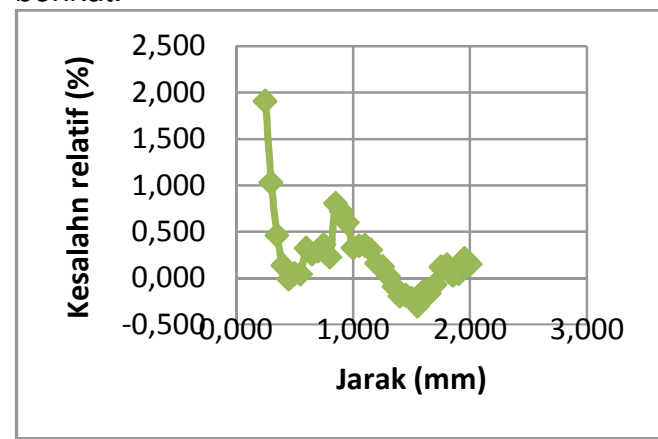

Gambar 15. Kesalahan relatif pada daerah sensitivitas maksimum sensor koil datar arah $\mathrm{y}$.

Dari grafik di atas, dapat diketahui kesalahan relatif maksimum sensor koil datar arah y adalah $1.91 \%$.

\section{Karakteristik Dinamis Sensor Dua Dimensi 2-D}

Kalibrasi dilakukan dengan memberikan masukan pada rangkaian interface yang berasal dari output sensor koil datar, kemudian rangkaian interface merekam dan menampilkan data hasil akuisisi data pada PC. Kalibrasi dilakukan untuk sensor arah $\mathrm{x}$ dan $\mathrm{y}$. Berikut gambar rangkaian sistem kalibrasi sensor seperti tampak pada gambar di bawah ini.

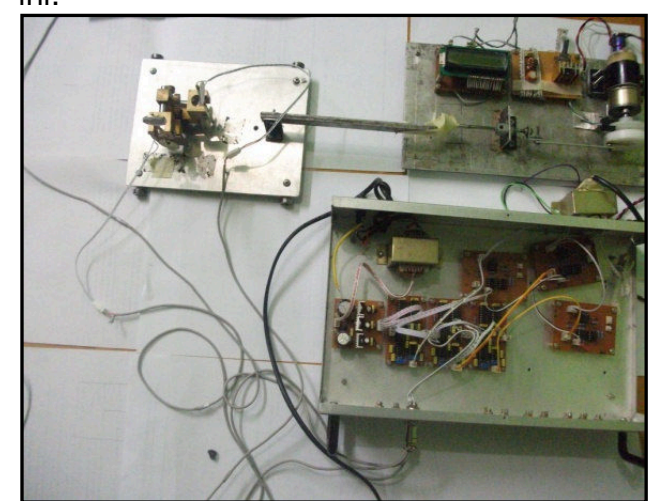

Gambar 16. Rangkaian sistem sensor untuk proses kalibrasi sensor koil datar dua dimensi (2-D)

Hasil kalibrasi sensor arah $\mathrm{x}$ tampak pada Tabel 1 berikut. 
Tabel 1. Karakteristik Dinamis Frekuensi Sensor Arah x Terhadap Frekuensi Sumber

\begin{tabular}{lll}
\hline $\begin{array}{l}\text { Frekuensi } \\
(\mathrm{Hz})\end{array}$ & $\begin{array}{c}\text { Sumber } \\
(\mathrm{Hz})\end{array}$ & $\begin{array}{l}\text { Frekuensi } \\
0.26\end{array}$ \\
0.35 & 0.31 & Sensor \\
0.40 & 0.39 \\
0.46 & 0.47 \\
0.50 & 0.47 \\
0.55 & 0.55 \\
0.62 & 0.62 \\
0.71 & 0.70 \\
0.76 & 0.78 \\
0.86 & 0.85 \\
0.95 & 0.94 \\
1.00 & 1.02 \\
1.11 & 1.09 \\
1.25 & 1.25 \\
\hline
\end{tabular}

Adapun Hasil kalibrasi sensor arah y tampak pada Tabel 2 berikut.

\begin{tabular}{|c|c|c|c|}
\hline $\begin{array}{l}\text { Frekuensi } \\
(\mathrm{Hz})\end{array}$ & Sumber & $\begin{array}{l}\text { Frekuensi } \\
(\mathrm{Hz})\end{array}$ & sensor \\
\hline 0.2 & & 0.23 & \\
\hline 0.31 & & 0.31 & \\
\hline 0.34 & & 0.39 & \\
\hline 0.4 & & 0.47 & \\
\hline 0.5 & & 0.5468 & \\
\hline 0.57 & & 0.625 & \\
\hline 0.76 & & 0.86 & \\
\hline 0.8 & & 0.86 & \\
\hline 0.83 & & 0.94 & \\
\hline 0.86 & & 0.94 & \\
\hline 0.9 & & 0.94 & \\
\hline 0.95 & & 1.02 & \\
\hline 1 & & 1.02 & \\
\hline 1.1 & & 1.117 & \\
\hline 1.17 & & 1.25 & \\
\hline 1.25 & & 1.33 & \\
\hline
\end{tabular}

Kalibrasi dinamis sensor arah $\mathrm{x}$
Adapun grafik tegangan keluaran terhadap jarak pada salah satu sampel frekuensi sumber $0,46 \mathrm{~Hz}$ untuk sensor arah $\mathrm{x}$ tampak pada gambar di bawah ini.

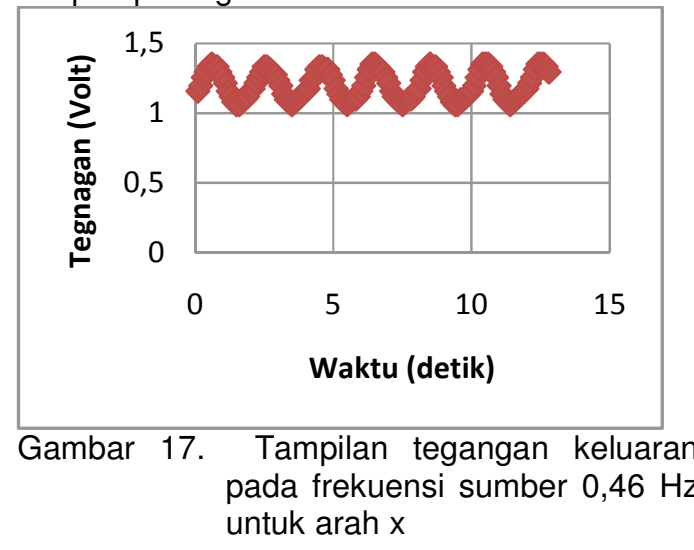

Dengan menggunakan Fast Transform Fourier (FFT) menggunakan program Ms. Excel, grafik di atas dapat ditentukan frekuensi dan amplitudo getaran sensor. Berikut grafik FFT untuk fekuensi sumber $0,46 \mathrm{~Hz}$.

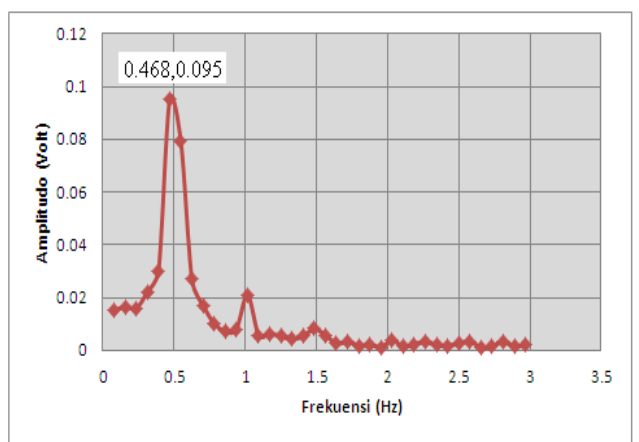

Gambar 18. FFT pada frekuensi sumber 0,46 $\mathrm{Hz}$.

Dari Gambar 18 di atas frekuensi sensor sebesar 0,468 Hz dengan amplitudo 0,095 Volt. Hal ini menunjukkan bahwa frekuensi yang diukur oleh sensor memiliki nilai yang sama dengan frekuensi sumber. Dengan demikian sensor getaran ini sudah cukup baik sebagai alat pengukur frekuensi getaran.

Berdasarkan Tabel 1 di atas, jika digambarkan secara grafik maka hubungan antara frekuensi yang dihasilkan sensor dengan frekuensi sumber tampak pada gambar di bawah ini. 


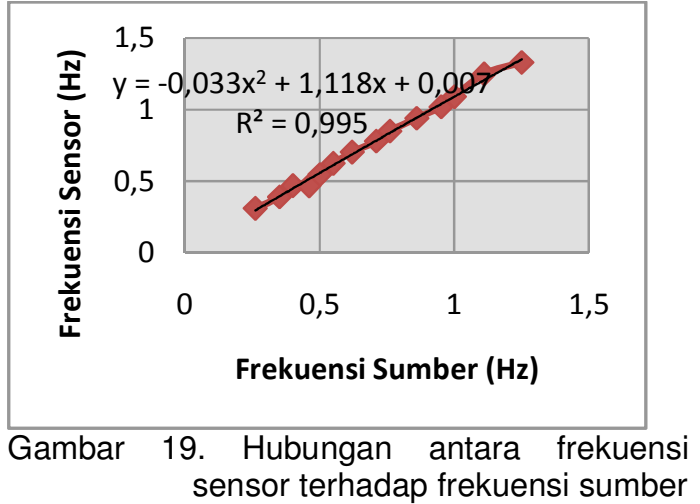

Adapun kesalahan absolut kesalahan absolut Gambar 19 di atas tampak pada kurva di bawah ini.

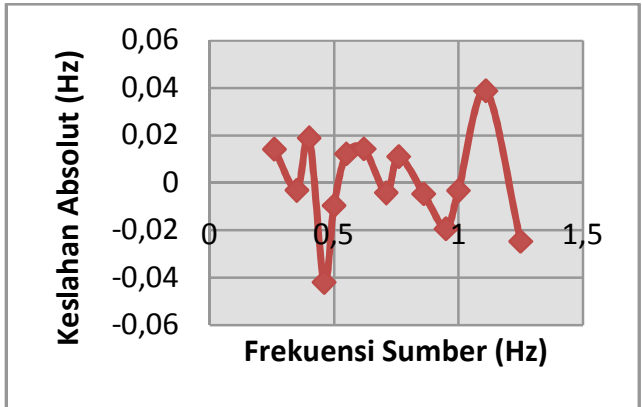

Gambar 20. Kesalahan absolut frekuensi sensor terhadap frekuensi sumber

Berdasarkan Gambar 20 di atas, dapat ditentukan bahwa penyimpangan pengukuran frekuensi sensor sebesar $0,042 \mathrm{~Hz}$ terhadap frekuensi sumber. Adapun kesalahan relatif pengukuran tampak pada gambar di bawah ini.

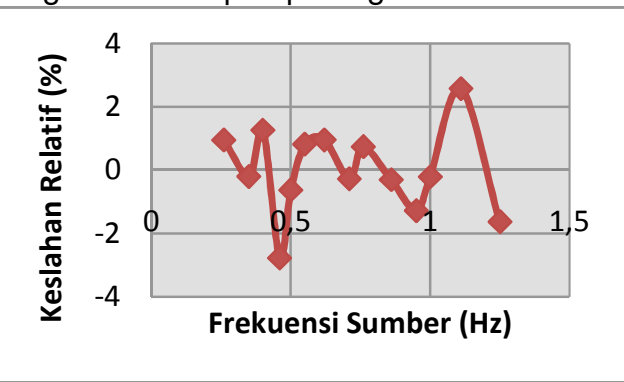

Gambar 21. Kesalahan relatif frekuensi sensor terhadap frekuensi sumber

Dengan memperhatikan gambar di atas dapat ditentukan bahwa kesalahan relatif paling besar adalah 2,78\%. Hasil ini cukup bagus karena rentang nilainya masih di bawah $5 \%$ kesalahan relatif maksimum.

Kalibrasi dinamis sensor arah y

Adapun grafik tegangan keluaran terhadap jarak pada salah satu sampel frekuensi sumber $0,5 \mathrm{~Hz}$ untuk sensor arah y tampak pada gambar di bawah ini.

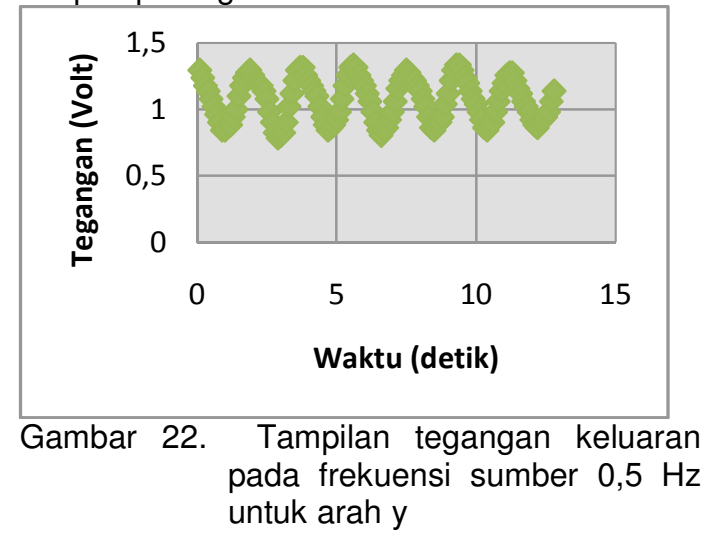

Dengan menggunakan Fast Transform Fourier (FFT) menggunakan program Ms. Excel, grafik di atas dapat ditentukan frekuensi dan amplitudo getaran sensor. Berikut grafik FFT untuk fekuensi sumber $0,5 \mathrm{~Hz}$.

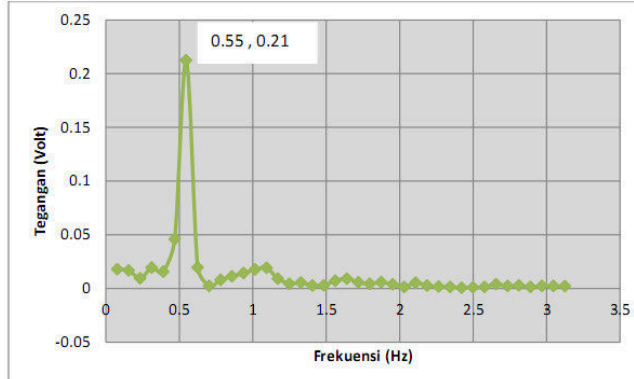

Gambar 23. FFT pada frekuensi sumber 0,5 $\mathrm{Hz}$.

Dari Gambar 23 di atas frekuensi sensor sebesar $0,55 \mathrm{~Hz}$ dengan amplitudo 0,21 Volt. Hal ini menunjukkan bahwa frekuensi yang diukur oleh sensor memiliki nilai yang sama dengan frekuensi sumber. Dengan demikian sensor getaran ini sudah cukup baik sebagai alat pengukur frekuensi getaran.

Berdasarkan Tabel 2 di atas, jika digambarkan secara grafik maka hubungan antara frekuensi yang dihasilkan sensor dengan frekuensi sumber tampak pada gambar di bawah ini. 


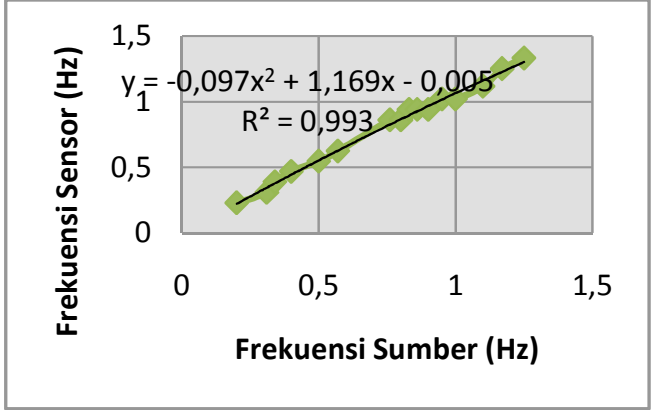

Gambar 24. Hubungan antara frekuensi sensor terhadap frekuensi sumber pada arah y

Adapun kesalahan absolut kesalahan absolut Gambar 24 di atas tampak pada kurva di bawah ini.

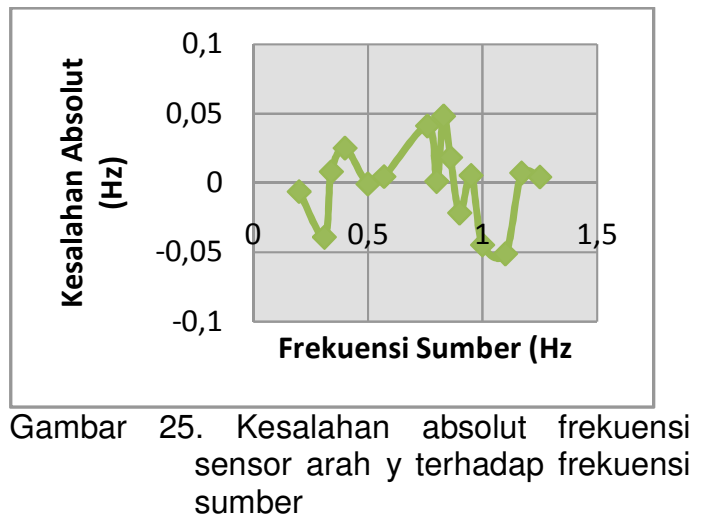

Berdasarkan Gambar 25 di atas, dapat ditentukan bahwa penyimpangan pengukuran frekuensi sensor sebesar $0,05 \mathrm{~Hz}$ terhadap frekuensi sumber. Adapun kesalahan relatif pengukuran tampak pada gambar di bawah ini.

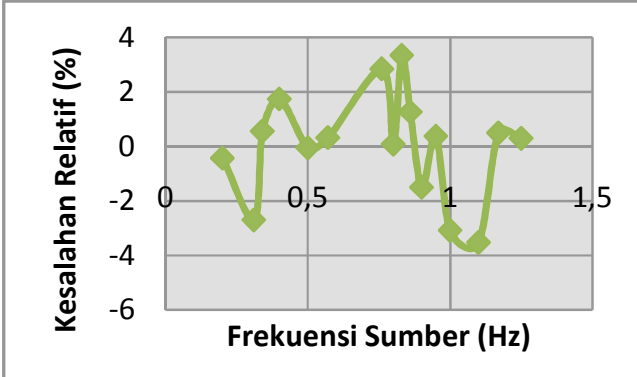

Gambar 26. Kesalahan relatif frekuensi sensor terhadap frekuensi sumber arah y

Dengan memperhatikan gambar di atas dapat ditentukan bahwa kesalahan relatif paling besar adalah 3,52\%. Hasil ini cukup bagus karena rentang nilainya masih di bawah $5 \%$ kesalahan relatif maksimum.

\section{Produk Alat Sensor Getaran Gempa}

Box rangkaian sensor. Box rangkaian yang telah dibuat pada penelitian ini antara lain berisi trafo, power supply, rangkaian pengolah sinyal, dan rangkaian pemutlak tegangan. Adapun detail gambar dari box rangkaian tampak pada Gambar 27 berikut.

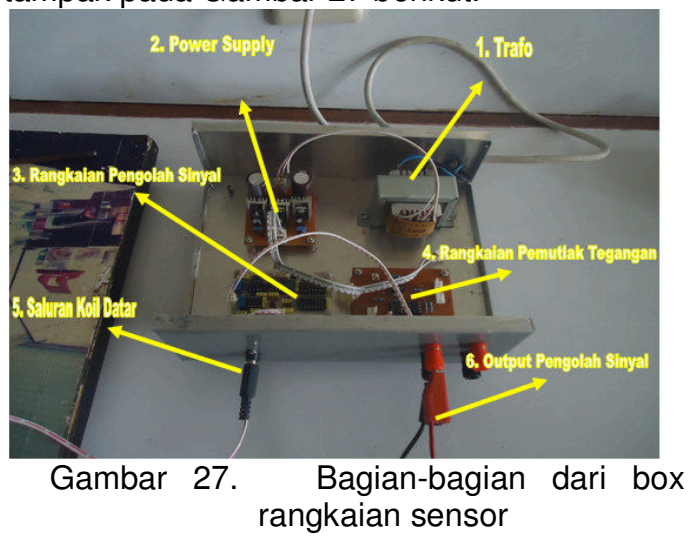

Bandul Mekanik sensor. Bandul mekanik yang telah dibuat terdiri atas tiang statif, alas beroda, penjepit statif, dan bandul matematis yang bias berayun secara periodik. Adapun bentuk bandul mekanik sensor tampak pada Gambar 28 berikut.

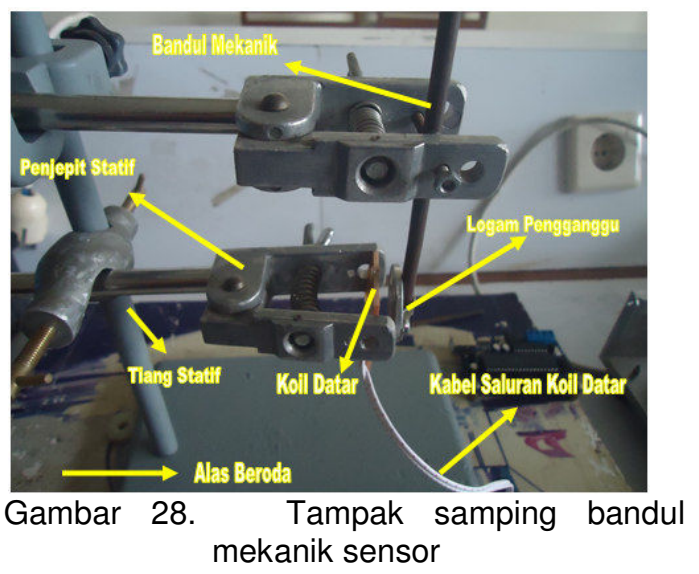

Mikrokontroler Atmega 16.

Adapun bentuk rangkaian mikrokontroler Atmega 16 tampak pada Gambar 18 berikut. 


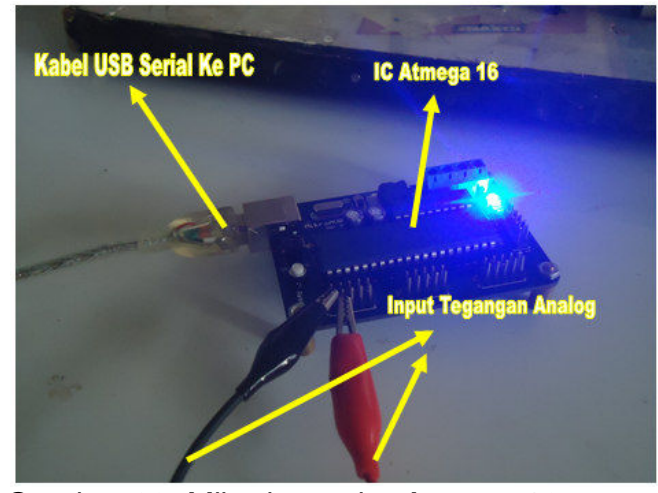

Gambar 29. Mikrokontroler Atmega 16

Mikrokontroler Atmega 16 berfungsi untuk merubah tegangan keluaran analog sensor menjadi tegangan digital (ADC) agar tegangan keluaran sensor dapat direkam dan ditampilkan bentuk gelombang getarannya pada PC.

Tampilan gelombang pada PC.

Bentuk gelombang tegangan keluaran sensor yang tampil pada PC dibuat menggunakan bahasa Pemgrograman Procesing. Adapun tampilan keluarannya tampak pada Gambar 30 berikut.

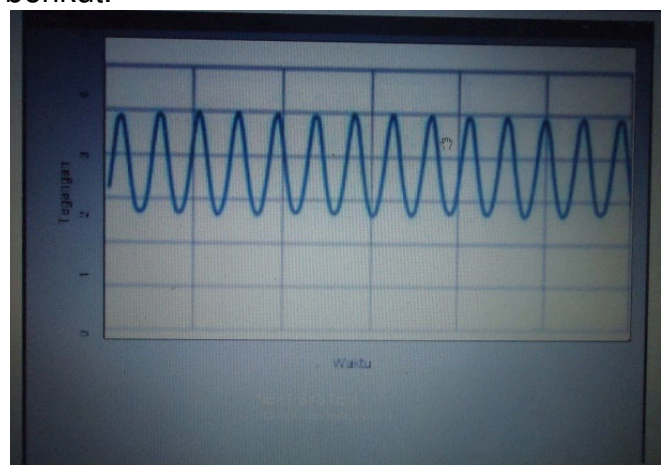

Gambar 30. Bentuk gelombang tegangan keluaran sensor
Produk Sensor Getaran Dua Dimensi (2-D) Berbasis Koil Datar

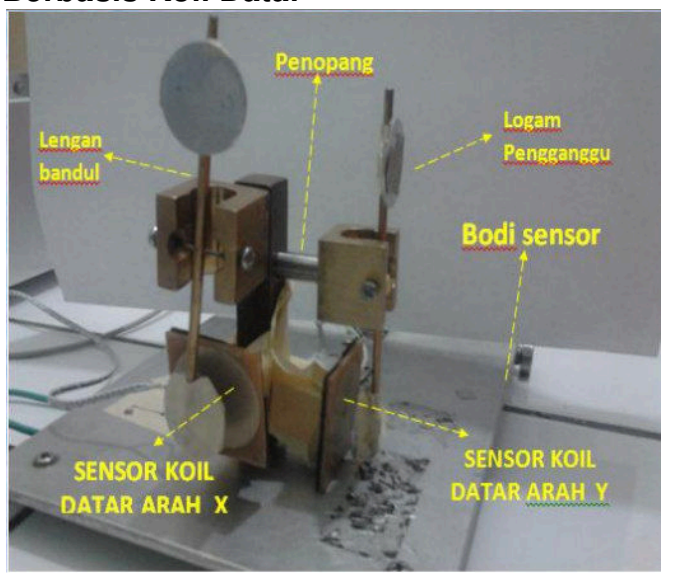

Gambar 31. Mekanik Sensor Getaran 2-D

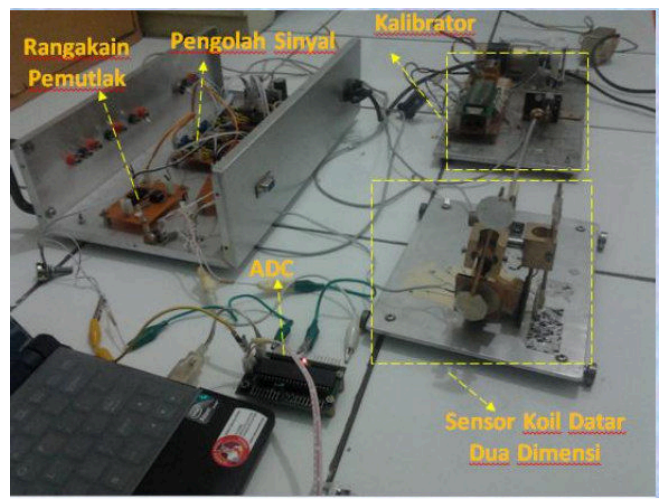

Gambar 32. Mekanik Sensor Getaran 2-D yang dihubungkan ke Kalibrator

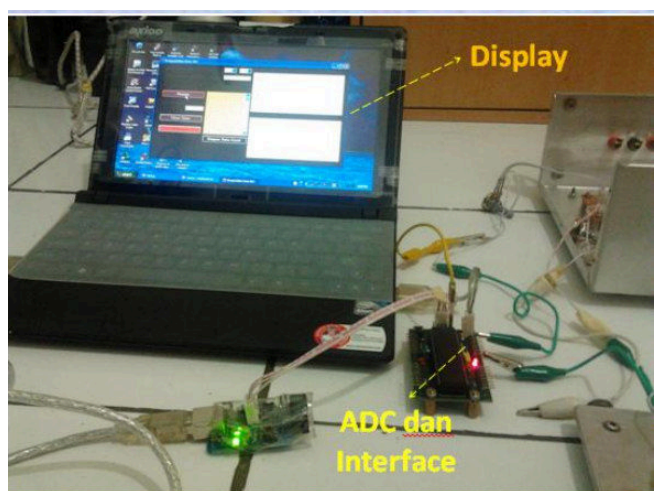

Gambar 33. Tampilan Output sensor getaran 2-D pada LCD 
B. Pembahasan Prinsip Kerja Sistem Sensor Dua Dimensi (2-D) Berbasis Koil Datar

Kalibrator menggerakkan bodi sensor sehingga bergerak secara periodik. Frekuensi gerakan bodi sensor diatur dari rentang $0,2-1,0 \mathrm{~Hz}$ yang terdapat pada display kalibrator. Bergeraknya bodi sensor akan mengakibatkan kedua bandul matematis ikut bergerak pada arah $\mathrm{x}$ dan arah y. Pergerakan periodik bandul menyebabkan logam pengganggu pada bandul akan bergerak menjauh dan mendekati sensor koil datar. Proses menjauh dan mendekatnya logam pengganggu terhadapa koil datar akan merubah nilai induktansi total sensor koil datar. Perubahan nilai induktansi total koil datar oleh rangkaian pengolah sinyal analog, dirubah menjadi nilai tegangan DC. Tegangan DC akan diakuisisi oleh ADC sehingga hasinya akan ditampilkan pada display.

Uji karakteristik statis sensor getaran arah $x$ dan y dilakukan menggunakan mikrometer sekrup digital dengan memberikan rentang jarak antara 0-15 $\mathrm{mm}$ dengan interval pengukuran sebesar $0,05 \mathrm{~mm}$. Rentang jarak $0-15 \mathrm{~mm}$ dan interval ini dilakukan pada ketiga sensor koil datar. Koil datar yang digunakan terbuat dari PCB dengan jumlah lilitan sebanyak 30 lilitan dan berdiameter $3 \mathrm{~cm}$. Bahan pengganggu terbuat dari bahan logam aluminium 500 rupiah yang masing-masing permukaannya sudah dihaluskan terlebih dahulu.

Berdasarkan grafik sensor hasil pengukuran Gambar 8 dan Gambar 9 di atas tampak bahwa tegangan keluaran sensor semakin kecil jika jarak antara sensor dengan bahan pengganggu semakin besar, begitu juga sebaliknya. Dari grafik tersebut diperoleh bawah ada dua macam tegangan yang diperoleh, yaitu tegangan keluaran yang bernilai positif dan tegangan keluaran yang bernilai negatif. Pada daerah tegangan keluaran yang bernilai positif terjadi nilai tegangan keluaran yang cenderung konstan, yaitu pada jarak yang semakin jauh dengan koil datar (saturasi). Pada daerah ini perubahan tegangan keluaran akibat perubahan jarak tidak begitu sensitif. Sedangkan pada tegangan keluaran negatif, tegangan keluaran cenderung linier terhadap jarak. Pada jarak yang cukup dekat antara koil datar dengan bahan pengganggu, terjadi perubahan tegangan secara drastis, yaitu tegangan tidak linier lagi. Daerah linier ini merupakan yang dapat menggambarkan respon sensor terhadap objeknya. Daerah ini disebut dengan daerah kerja sensor. Daerah kerja diambil berdasarkan pola yang dibentuk dari kurva tersebut apakah dapat didekati dengan suatu fungsi atau tidak. Fungsi yang paling sering digunakan adalah fungsi liner, akan tetapi untuk lebih mendapatkan hasil yang lebih baik dapat juga didekati dengan fungsi polinomial orde banyak dan fungsi lainnya.

Berdasarkan grafik pada Gambar 10 dan Gambar 11 di atas, tampak bahwa daerah kerja sensor arah $\mathrm{x}$ dan arah y yang dapat diambil adalah antara $0.250-4.050 \mathrm{~mm}$. Kurva pada daerah tersebut membentuk hasil yang kontinu sehingga diperkirakan dapat didekati dengan suatu fungsi dengan baik. Daerah kurva yang lebih kecil dari $0.250 \mathrm{~mm}$ terlihat sudah mulai mengalami nilai yang tetap (saturasi) sehingga tidak kontinu dengan data yang lainnya, sehingga hal ini akan sulit untuk didekati dengan suatu fungsi. Oleh karena itu, data pada daerah ini tidak dimasukkan pada daerah kerja dari sensor. Dengan menggunakan persamaan polynomial orde 3 , maka diperoleh suatu pendekatan yang sangat baik untuk mendekati grafik sensitifitas keluaran masing-masing sensor. Adapun untuk persamaan polynomial sensor getaran arah $\mathrm{x}$ adalah:

$d=0.0024 V_{o}^{3}+0.0436 V_{o}^{2}+0.4926 V_{o}+$ 2.6049; dengan tingkat korelasi $\mathrm{R}^{2}=0.9996$.

dimana $d$ dan Vo masing-masing dalam satuan $\mathrm{mm}$ dan Volt. Tampak gambar $7 \mathrm{di}$ atas persamaan yang digunakan sangat mendekati data yang diperoleh. Sedangkan sensor getaran arah y persamaan polynomialnya adalah:

$d=0.0023 V_{o}^{3}+0.0403 V_{o}^{2}+0.4567 V o+$ 2.5493;

dengan tingkat korelasi $\mathrm{R}^{2}=0.9998$.

dimana $d$ dan Vo masing-masing dalam satuan $\mathrm{mm}$ dan Volt. Tampak dari ketiga sensor tersebut, persamaan yang digunakan sangat mendekati data yang diperoleh.

Uji karakteristik dinamis yang sudah dilakukan, kalibrasi pada sensor koil datar dilakukan dengan memberikan getaran dengan amplitudo dan frekuensi tertentu pada sensor. Getaran yang dideteksi berasal dari 
vibrator yang sudah diatur frekuensinya. Gerakan logam pengganggu menjauh dan mendekat terhadap koil datar menghasilkan tegangan keluaran pada sensor yang membentuk pola gelombang sinusoidal yang akan diukur frekuensinya. Kalibrasi sensor dengan amlitudo sumber getaran $1 \mathrm{~cm}$. Kalibrasi dengan amplitudo tetap, dilakukan dengan memberikan getaran pada sensor yang berasal dari sumber penggetar. Frekuensi sumber getaran dapat diatur nilai frekuensinya mulai dari 0 sampai frekuensi maksimum $1 \mathrm{~Hz}$. Nilai amplitudo dibuat tetap dengan nilai sebesar $1 \mathrm{~cm}$. Frekuensi sumber getaran yang digunakan pada sensor arah $\mathrm{x}$ antara lain $0,26 \mathrm{~Hz} ; 0,35 \mathrm{~Hz} ; 0,4 ; \mathrm{Hz} ; 0,46 \mathrm{~Hz}$; $0,5 \mathrm{~Hz} ; 0,55 \mathrm{~Hz} ; 0,62 \mathrm{~Hz} ; 0,71 \mathrm{~Hz} ; 0,76 \mathrm{~Hz}$; dan $0,86 \mathrm{~Hz} ; 0,95 \mathrm{~Hz} ; 1,0 \mathrm{~Hz} ; 1,11 \mathrm{~Hz}$; dan $1,25 \mathrm{~Hz}$. Adapun frekuensi sumber yang digunakan pada sensor arah y antara lain 0,20 $\mathrm{Hz}$; 0,31 Hz; 0,40 Hz; 0,50 Hz; 0,57 Hz; 0,76 $\mathrm{Hz} ; 0,80 \mathrm{~Hz} ; 0,83 \mathrm{~Hz} ; 0,86 \mathrm{~Hz} ; 0,90 \mathrm{~Hz} ; 0,95$ $\mathrm{Hz} ; 1,0 \mathrm{~Hz} ; 1,11 \mathrm{~Hz}$; dan $1,25 \mathrm{~Hz}$.

Tampak dari Gambar 19 di atas, frekuensi yang dihasilkan oleh sensor arah $\mathrm{x}$ hampir sama dengan frekuensi sumber. Ketika frekuensi sumber bertambah, maka frekuensi sensor juga semakin besar. Jika didekati dengan kurva linier, hubungannya cukup linier dengan nilai $R^{2}=0,9954$. Hal ini menunjukkan bahwa terdapar respon yang sangat bagus antara frekuensi sumber dengan frekuensi yang dihasilkan sensor. Hal yang sama juga diperoleh pada sensor arah y.

Berdasarkan hasil yang diperoleh seperti pada Tabel 1 dan Tabel 2 di atas, tampak bahwa nilai frekuensi sumber vibrator hampir sama dengan nilai frekuensi yang diukur oleh sensor getaran. Hal ini terlihat dengan jelas dengan memperhatikan Gambar 15 di atas bahwa kesalahan relatif paling besar adalah $2,78 \%$. Hasil ini cukup bagus karena rentang nilainya masih di bawah $5 \%$ kesalahan relatif maksimum.

Produk sensor getaran yang tampak bahwa sensor getaran yang telah dibuat dalam penelitian terdiri dari box rangkaian sensor, bandul mekanik sensor, mikrokontroler Atmega 16 (Analog to Digital Converter), dan PC sebagai tempat untuk menampilkan bentuk gelombang dari suatu yang getaran yang sedang dideteksi oleh sensor koil datar. Box rangkaian yang telah dibuat pada penelitian ini antara lain berisi trafo, power supply, rangkaian pengolah sinyal, dan rangkaian pemutlak tegangan. Fungsi masing-masing komponen antara lain: (1)trafo berfungsi untuk menurunkan tegangan PLN; (2) power Supply berfungsi untuk merubah tegangan $A C$ (PLN) menjadi tegangan $D C$ sehingga keluaran $D C$ pada power supply antara lain $-9 \mathrm{~V},+9 \mathrm{~V},+5$ V, dan $0 \mathrm{~V}$; (3) rangkaian Pengolah Sinyal berfungsi untuk merubah adanya perubahan induktansi koil datar akibat logam pengganggu menjadi tegangan keluaran (Vo) DC; (4) rangkaian pemulak tegangan berfungsi untuk memutlakkan tegangan keluaran pengolah sinyal yang bernilai negaif menjadi tegangan keluaran yang bernilai positif. Hal ini karena jika tegangan keluaran bernilai negative, maka Atmega 16 akan membacanya sebagai tegangan 0 volt; (5) Saluran Koil Datar berfungsi sebagai saluran penghubung antara rangkaian pengolah sinyal dengan koil datar yang berada pada mekanik sensor; (6) Ouput pengolah sinyal berfungsi sebagai keluaran dari pengolah sinyal ke Mikrokontroler Atmaega 16 yang sebelumnya sudah dimutlakkan oleh rangkaian pemutlak tegangan.

Selain itu, bandul mekanik yang telah dibuat terdiri atas tiang statif, alas beroda, penjepit statif, dan bandul matematis yang bias berayun secara periodik. Bandul mekanik sensor pada gambar di atas hanya mendeteksi getaran hanya dalam arah 1 dimensi. Bandul ini akan berayun bolak balik secara periodik jika mendeteksi adanya getaran objek tempat bandul itu berada. Untuk mendeteksi adanya gempa yang terjadi, maka bandul tersebut diletakkan di atas permukaan tanah. Jika tanah bergetar akibat adanya gempa, maka bandul juga akan iku bergetar. Semakin besar frekuensi getaran pada tanah, maka semakin besar juga frekuensi getaran pada bandul. Hal ini ditunjukkan dengan semakin keras ayunan logam pengganggu mendekati dan menjauhi koil datar secara periodik. Dengan menjauh atau mendekatnya dan mendekatnya logam pengganggu, mengakibatkan adanya perubahan tegangan keluaran sensor yang akan direkam dan ditampilkan pada PC. Agar bandul bisa berayun dengan baik, kondisi batang bandul harus terlebih dahulu dalam posisi tegak seperti pada gambar di atas dan dibuat seimbang antara batang bandul bagian atas dengan batang bandul bagian bawah. Untuk menyeimbangkan batang bandul ini 
dilakukan dengan merubah posisi logam pengganggu ke atas atau ke bawah. Oleh karena itu, logam pengganggu yang telah dibuat pada penelitian ini bisa digeser kedudukannya menggunakan penjepit yang ada dibelakang logam.

Pada penelitian ini, akuisisi data dilakukan dengan interface mikrokontroler Atmega 16. Mikrokontroler Atmega 16 berfungsi untuk merubah tegangan keluaran analog sensor menjadi tegangan digital (ADC) agar tegangan keluaran sensor dapat direkam dan ditampilkan bentuk gelombang getarannya pada PC. Berdasarkan Gambar 18 di atas dapat dengan jelas terlihat bagian-bagian komponen dari mikrokontroler Atmega 16. Adapun fungsi masing-masing komponen tersebut antara lain: input tegangan analog merupakan tegangan keluaran pengolah sinyal sensor yang masih bersifat analog yang nilai tegangannya berkisar dari 0-5 volt. IC Atmega 16 akan mengkonversi tegangan analog tersebut menjadi tegangan digital melalui ADC (Analog to Digital Converter). Tegangan yang sudah dikonversi ini yang diteruskan ke PC melalui Kabel USB Serial.

Adapun bentuk gelombang tegangan keluaran sensor yang tampil pada PC dibuat menggunakan bahasa Pemgrograman Procesing. Pembuatan bahasa pemrograman ini membutuhkan waktu yang cukup lama sekitar 3 bulan. Bahasa pemrograman berfungsi untuk menampilkan data tegangan keluaran yang sudah direkam oleh mikrokontroler kemudian data tersebut ditampilkan pada PC agar bentuk gelombang tegangan keluaran sensor terhadap waktu dapat dillihat secara langsung. Berdasarkan gambar 19 di atas, tampak bahwa bentuk gelombang pada PC berbentuk sinusoidal. Bentuk gelombang yang ditampilkan di atas menggambarkan suatu objek yang bergetar yang sedang dideteksi oleh sensor. Bentuk gelombang pada gambar di atas sebenarnya merupakan getaran yang berasal dari vibrator yang nilai frekuensinya sudah ditentukan. Tampak pada gambar di atas, gelombang yang tampil merupakan tegangan keluaran sensor terhadap waktu. Waktu yang dimaksudkan pada gambar di atas adalah waktu untuk mencacah tegangan. Waktu yang digunakan untuk mencacah tegangan keluaran berkisar dalam orde ms (milisekon). Pada penelitian ini, pada procesing waktu cacah yang digunakan adalah $100 \mathrm{~ms}$. Dengan menggunakan waktu cacah yang sangat pendek ini, rekaman data pada excel memiliki jumlah yang sangat banyak (orde ratusan/ribuan). Semakin kecil waktu cacah yang digunakan maka semakin banyak data yang terekam, sehingga bentuk gelombang tegangan terhadap waktu juga semakin bagus. Bentuk gelombang yang direkam bisa memiliki bentuk sinusoidal maupun bentuk yang lain. $\mathrm{Hal}$ ini sangat tergantung pada kondisi gerakan dari objek yang sedang dideteksi oleh sensor.

\section{KESIMPULAN}

Berdasarkan hasil penelitian, kesimpulan yang diperoleh antara lain: (1) sensor getaran untuk mendeteksi gempa bumi sudah dirancang dan sudah dikalibrasi. Sensor getaran yang sudah dibuat merupakan sensor getaran yang bentuknya dua dimensi (2-D) yaitu sensor getaran arah $\mathrm{x}$ dan arah $\mathrm{y}$. Adapun komponen-komponen dari sensor yang telah dibuat antara lain box rangkaian, bandul mekanik sensor, mikrokontroler Atmega 16, serta tampilan gelombang getaran objek pada PC; (2) frekuensi sumber pada sensor arah $\mathrm{x}$ untuk getaran objek yang sudah diukur antara lain $0,26 \mathrm{~Hz} ; 0,35 \mathrm{~Hz} ; 0,4 ; \mathrm{Hz}$; $0,46 \mathrm{~Hz} ; 0,5 \mathrm{~Hz} ; 0,55 \mathrm{~Hz} ; 0,62 \mathrm{~Hz} ; 0,71 \mathrm{~Hz}$; $0,76 \mathrm{~Hz} ; 0,86 \mathrm{~Hz} ; 0,95 \mathrm{~Hz} ; 1,0 \mathrm{~Hz} ; 1,11 \mathrm{~Hz}$; dan $1,25 \mathrm{~Hz}$. Salah satu sampel frekuensi getaran yang sudah bisa diukur adalah 0,468 $\mathrm{Hz}$. Nilai ini hampir sama dengan frekuensi sumber getaran sebesar $0,46 \mathrm{~Hz}$; sedangkan frekuensi sumber pada sensor arah y untuk getaran objek yang sudah diukur antara lain $0,20 \mathrm{~Hz} ; 0,31 \mathrm{~Hz} ; 0,40 \mathrm{~Hz} ; 0,50 \mathrm{~Hz} ; 0,57 \mathrm{~Hz}$; $0,76 \mathrm{~Hz} ; 0,80 \mathrm{~Hz} ; 0,83 \mathrm{~Hz} ; 0,86 \mathrm{~Hz} ; 0,90 \mathrm{~Hz}$; $0,95 \mathrm{~Hz} ; 1,0 \mathrm{~Hz} ; 1,11 \mathrm{~Hz}$; dan $1,25 \mathrm{~Hz}$. Salah satu sampel frekuensi getaran yang sudah bisa diukur adalah $0,55 \mathrm{~Hz}$. Nilai ini hampir sama dengan frekuensi sumber getaran sebesar $0,50 \mathrm{~Hz}$; (3) sensor getaran dua dimensi (2-D) ini sudah mengalami proses penyempurnaan lebih lanjut, antara lain menentukan daerah kerja sensor, menampilkan hasil pengukuran frekuensi secara langsung pada PC menggunakan bahasa pemrograman berbasis Procesing, dan sudah dibuat rumahan sensor getaran berbasis koil datar yang lebih efesien dan efektif. 
Adapun saran yang dapat dikemukakan antara lain:(1)perlu menggunakan sumber getaran dari frekuensi dari $1 \mathrm{~Hz}$ sampai dengan $100 \mathrm{~Hz}$; (2)perlu pengembangan lebih lanjut pada sensor ini dengan cara menjalin kerjasama dengan disiplin ilmu yang serumpun maupun kerjasama dengan institusi lain baik dengan universitas lain, BMKG, maupun dengan instansi lain; (3) peneliti mengharapkan agar Direktorat Penelitian dan Pengabdian Kepada Masyarakat Direktorat Jenderal Pendidikan Tinggi, Kementerian Pendidikan dan Kebudayaan selanjutnya mendukung penelitian ini supaya bisa dikembangkan menjadi sensor getaran tiga dimensi (3-D) yang lansung dihubungkan ke server internet.

\section{DAFTAR PUSTAKA}

Andrianto, Heri. 2008. Pemrograman Mikrokontroler AVR ATMEGA 16 Menggunakan Bahasa C (CodeVision AVR). Informatika. Bandung.

Djamal, Mitra. 1996. A Study of Flat Coil Sensor For Measuring Displacements. Journal Departement of Physics, Faculty of Mathematics and Sciences ITB.

Duncan, Tom. 1962. Electronics for Today and Tomorrow. John Murray (Publiser) Ltd. London.

Erik Hallen. 1962. Electromagnetic Theory. Chapman \& Hall Ltd., London.

Grant, L, S., Philips, W. R. 1996, Electromagnetisme. $2^{\text {nd }}$. Ed., John Wiley and Sons. Chycester.

Lazuardi. 1996. Studi Awal Sensor Getaran Berdasarkan Prinsip Induktif. Tesis . FMIPA ITB, Bandung.

Sardo Martinus. 1999. Studi Awal Pembuatan Prototipe Alat Ukur Kecepatan Aliran Udara Menggunakan Sensor Koil Datar. Laporan Tugas Akhir Program DIII Instrumentasi FMIPA UI, Depok.

Setiadi, Rahmon Nanda. 2009. Sensor Getaran Frekuensi Rendah Berbasis
Koil Datar. Tesis. FMIPA ITB, Bandung.

Sutrisno. 1986. Elektronika: Teori Dasar dan Penerapannya. Jilid I. Penerbit ITB. Bandung.

Sutrisno. 1986. Elektronika: Teori Dasar dan Penerapannya. Jilid II. . Penerbit ITB. Bandung.

Sutrisno. 1986. Modul Elektronika Lanjutan: Teori Dasar dan Penerapannya, Jurusan Fisika. Penerbit ITB. Bandung

Watiasih, richa. 2008. Penerapan LVDT Sebagai Sensor Getaran Pendeteksi Ketidakrapatan Berbasis Data Getaran Pada Komresor, POLITEKNIK Jurnal Teknologi, Volume 7, No 2, September 2008ISSN 1412-6427. Universitas Bhayangkara Surabaya.

Widanarto, Wahyu. 2000. Desain dan Pembuatan Alat Ukur Kecepatan Aliran Udara dengan Sensor Koil Datar berbasis Mikrokontroler 89c51. Tesis. FMIPA ITB, Bandung. 